\title{
Structural, Morphological and Electrochemical Examination of Carbon Spheres Wrapped by Maghemite Nanoparticles
}

\author{
P. Devendran, R. Ranjithkumar, C. Sambathkumar, V. Manirathinam, M. Krishnakumar
}

\begin{abstract}
In this work, pure carbon spheres (CSs) and $\mathrm{Mn}_{3} \mathrm{O}_{4}$ nanoparticles (NPs) embedded on carbon sphere were synthesized by hydrothermal method. The prepared $\mathrm{CS} / \mathrm{Mn}_{3} \mathrm{O}_{4}$ was examined with structural, functional, and morphological properties by $X R D, F T I R$, and SEM analysis. The average grain size and crystalline size of $\mathrm{Mn}_{3} \mathrm{O}_{4}$ coated carbon sphere were found through morphological analysis. The element ratio, composition and distribution of the prepared $\mathrm{Mn}_{3} \mathrm{O}_{4}$ coated carbon sphere were analyzed through EDS and Mapping analysis. Electrochemical performance such as redox behavior, charge storage/discharge capacity and resistive nature of $\mathrm{Mn}_{3} \mathrm{O}_{4} / \mathrm{CSS}$ was evaluated using cyclic voltammetry, chronopotentiometry, and electrochemical impedance spectroscopic analysis.
\end{abstract}

Keywords-- $\mathrm{Mn}_{3} \mathrm{O}_{4}$, Carbon sphere, $\mathrm{Mn}_{3} \mathrm{O}_{4} @$ carbon sphere, Electrochemical studies, Charge-discharge.

\section{INTRODUCTION}

Unique properties and applications of nanoscale materials made the field of nanotechnology and nanomaterials a growing interest in the past few decades. Some of examples includes 0D materials (quantum dots), 1D materials (carbon nanotubes, CNTs), 2D materials (Graphene), and 3D materials (Graphite). The various form of carbon derivatives is getting much interest among researchers working on nanotechnology field [1-7]. Among various segregations, the carbon spheres make promising nanomaterial in various applications. It can be prepared via various techniques such as arc discharge, laser ablation chemical vapour deposition methods, and hydrothermal respectively [8, 9]. Many nomenclature is given for spherical shaped carbon materials which includes carbon blacks, carbon balls, etc., [10] The

Revised Manuscript Received on December 16, 2019.

* Correspondence Author

P. Devendran*, Department of Physics, International Research Centre,Kalasalingam Academy of Research and Education, Krishnankoil - 626126.Tamil Nadu, India.pdevavenmani@gmail.com

R. Ranjithkumar, Department of Physics, International Research Centre,Kalasalingam Academy of Research and Education,

Krishnankoil - 626126.Tamil Nadu, India.

C. Sambathkumar, Department of Physics, International Research Centre,Kalasalingam Academy of Research and Education,

Krishnankoil - 626126.Tamil Nadu, India.

V. Manirathinam, Department of Physics, International Research Centre,Kalasalingam Academy of Research and Education, Krishnankoil - 626126.Tamil Nadu, India.

M. Krishnakumar, Department of Physics, International Research Centre,Kalasalingam Academy of Research and Education,

Krishnankoil - 626126.Tamil Nadu, India. potential applications acquired from these materials are many that includes wide variety of physical properties and outstanding mechanical properties [4]. A large number of technical applications includes electron field emitters, gas sensor, nano-electronic devices, energy storage devices such as supercapacitor have been demonstrated [11-13].

Based on the major excellent physic-chemical property, the transition metal oxides were of significant interest for the researches that provides way for various applications [14-16]. The preparation of metal oxide nanomaterials in the few nanometric sizes would enhance the additional properties that are possessed by the material [17]. Among most transition metal oxides, the most notable transition metal is the manganese oxide which is a promising electrode material for electrochemical devices as it possesses large theoretical capacity $(\sim 1370 \mathrm{~F} / \mathrm{g})$ with affordable price and environment friendliness [18, 19]. Though it has maximum theoretical capacitance value, some of the drawback like poor conductivity, minimum ion diffusion etc., respectively made the material to exhibit quite lower specific capacitance reported so far comparing the theoretical value. Until today many forms of manganese oxide were reported in order to improve the specific capacitance values.

Present work, we reported the combination of transition metal oxides embedded on carbon spheres. Comparing all other techniques, the mild hydrothermal synthesis was simple and user friendly method. Various analytical techniques were undertaken for the prepared material to analyse different properties. In addition, the electrochemical studies were made to interpret redox properties, charge-discharge mechanism and conductivity nature of prepared pure and $\mathrm{Mn}_{3} \mathrm{O}_{4} / \mathrm{CSs}$. To the best of our knowledge there has been no report yet on combination of manganese oxide with $\mathrm{Mn}_{3} \mathrm{O}_{4}$ structure on to the surface of carbon sphere for evaluation of electrochemical activity.

\section{EXPERIMENTAL SECTION}

\section{A. Materials}

In order to prepare the sample, Glucose, $\mathrm{MnCl}_{2}, \mathrm{NaOH}$ and ethanol were purchased from Sisco Research Laboratories Pvt. Ltd., Mumbai, India. Analytical grade chemicals with high purity of $99 \%$ were used. Ultra-pure Millipore deionized (DI) water was used as a solvent for whole reaction. To do the electrochemical test, activated carbon (AC), potassium hydroxide

$(\mathrm{KOH})$

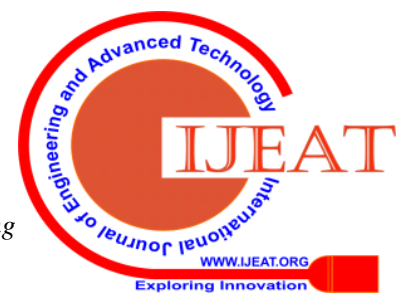



polyvinylidene fluoride $\left(\left(-\left(\mathrm{C}_{2} \mathrm{H}_{2} \mathrm{~F}_{2}\right)_{\mathrm{n}^{-}}-\right), \mathrm{PVDF}\right)$ were used and it obtained from Sigma-Aldrich (Mumbai).

\section{B. Materials characterization}

The bare carbon sphere was synthesized using $1 \mathrm{M}$ of glucose. It was dissolved in $125 \mathrm{ml}$ of DI water and continuously stirred until gets the homogeneous reaction mixture. Then the solution was transferred into the $150 \mathrm{ml}$ autoclave and kept undisturbed in oven at about $180^{\circ} \mathrm{C}$ for 12h. The obtained bare carbon sphere was cleaned and washed by centrifuging with DI water and ethanol for several times to remove extra additives. Following this, the sample was dried overnight in hot air oven at $80^{\circ} \mathrm{C}$ [20]. The $\mathrm{Mn}_{3} \mathrm{O}_{4}$ coated carbon sphere was prepared by taking prepared bare carbon sphere and $\mathrm{MnCl}_{2}$ in the equimolar ratio of $0.05 \mathrm{M}$ in $125 \mathrm{ml}$ DI water. The reaction mixture was kept in magnetic stirring for about half an hour. After complete dispersion and dissolution of bare carbon sphere and $\mathrm{MnCl}_{2}$ in the solvent, $0.1 \mathrm{M}$ of $\mathrm{NaOH}$ was added to adjust $\mathrm{pH}: 9$. Then the same procedure was carried out as like as the bare carbon sphere [21]. The entire procedure for preparation of $\mathrm{Mn}_{3} \mathrm{O}_{4}$ coated carbon sphere was shown in fig 1.

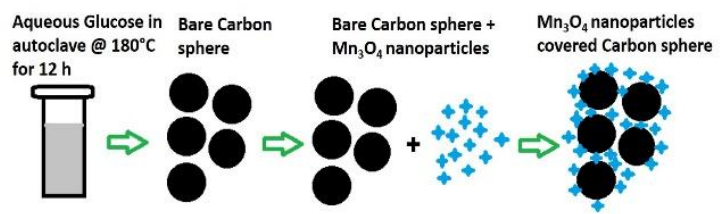

Fig. 1. Synthesis procedure of $\mathrm{Mn}_{3} \mathrm{O}_{4}$ embedded on carbon spheres nanocomposites.

\section{Modified electrode fabrication}

With the help of some reported procedures, modified working electrode was fabricated [22, 23]. In brief, the as prepared material with the weight ratio of $80 \%, \mathrm{AC}$ as conducting material was taken in the ratio $15 \%$ and $5 \%$ PVDF as a binder was used. All the three were mixed using NMP solvent and made into slurry. The formed slurry was coated on to the nickel foil with the area composed of $(1 \times 1 \mathrm{~cm})$. The resulting mixture on the substrate was dried in hot air oven at a temperature of about $60^{\circ} \mathrm{C}$ for $6 \mathrm{~h}$ to fabricate an electrode.

\section{CHARACTERIZATION}

\section{A. Structural analysis}

Using powder X-ray diffraction analysis Bruker X-ray diffractometer (D8 advance ECO) with monochromatic $\mathrm{Cu}-\mathrm{K} \alpha$ radiation containing $1.5406 \AA$ wavelengths, the crystal structure was determined. To study functional groups of the prepared sample fourier transform infrared spectrometer (FTIR) was employed using a Shimadzu (IR Tracer-100) spectrophotometer within the range of 4000-400 $\mathrm{cm}^{-}{ }^{1}$ using $\mathrm{KBr}$ pellet system. Bare and $\mathrm{Mn}_{3} \mathrm{O}_{4}$ covered carbon sphere formation was confirmed through the morphological analysis using Scanning Electron Microscope (SEM, ZEISS-EVO 18 Research, Japan) along with Energy Dispersive X-Ray analyses (EDS) (BRUKER-X Flash 6130). The mapping analysis reveals the purity of the prepared materials.
N-methyl-2-pyrrolidinone $\left(\mathrm{C}_{5} \mathrm{H}_{9} \mathrm{NO}, \quad \mathrm{NMP}\right) \quad$ and

\section{B. Electrochemical analysis}

Electrochemical behavior of the prepared $\mathrm{Mn}_{3} \mathrm{O}_{4} / \mathrm{CSs}$ was examined with the help of electrochemical workstation $(\mathrm{CH}$ Instruments-CHI 6008e, USA) at room temperature. A three-electrode system with modified electrode material employed as working electrode, a platinum $(\mathrm{Pt})$ wire as counter electrode and silver electrode $(\mathrm{Ag} / \mathrm{AgCl})$ as reference electrode was employed. An aqueous electrolyte solution utilized was $6 \mathrm{M} \mathrm{KOH}$.

\section{RESULTS AND DISCUSSION}

\section{A. Powder XRD analysis}

The PXRD pattern of prepared (a) bare carbon sphere (b) $\mathrm{Mn}_{3} \mathrm{O}_{4}$ covered carbon sphere was depicted in Fig. 2. A hump at 2 theta value of $20^{\circ}$ shown in fig. 2(a) reveals the PXRD pattern of pure carbon sphere. The 2 theta values were fixed between $10-80^{\circ}$.

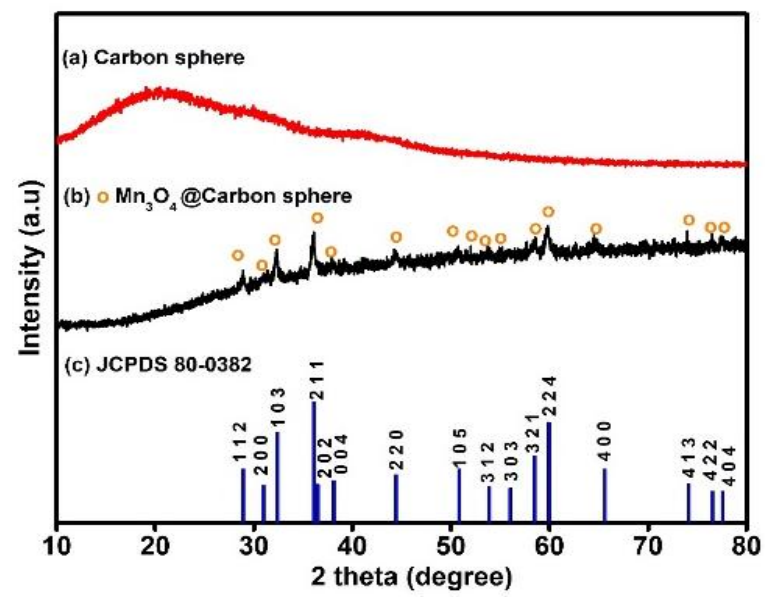

Fig. 2. XRD patterns of (a) bare carbon sphere (CSs) and (b) $\mathrm{Mn}_{3} \mathrm{O}_{4} /$ CSs nanocomposites.

The crystalline peaks of $\mathrm{Mn}_{3} \mathrm{O}_{4}$ were perfectly matched with the standard JCPDS card number 80-0382 depicted in fig. 1(b) [24]. Tetragonal structure with space group I41/and (141) was obtained. The maximum diffraction peaks were observed in $32.3,36.0,58.5,59.9,65.6^{\circ}$ with corresponding (h k l) indices (211), (103), (224), (400) and (112). The particles size of prepared $\mathrm{Mn}_{3} \mathrm{O}_{4} \mathrm{NPs}$ was found $\sim 10$ to $50 \mathrm{~nm}$ by SEM morphological analysis.

\section{B. FTIR analysis}

FTIR spectra of prepared (a) bare carbon sphere (b) $\mathrm{Mn}_{3} \mathrm{O}_{4}$ NPs evenly decorated on carbon spheres was revealed in fig. 3. The functional group, metal bond interactions such as bending and stretching vibrations between the molecules present were estimated using FTIR analysis. In finger print region, the metal oxide interactions i.e., $\mathrm{Mn}-\mathrm{O}$ bond vibrations were observed in peaks 630,524 , and $418 \mathrm{~cm}^{-1}$. In the wavenumber between $2881 \mathrm{~cm}^{-1}$ the $\mathrm{C}-\mathrm{H}$ bond stretch were seen. The triple bond formation of carbon-carbon atom was observed in peaks 2351 and $2312 \mathrm{~cm}^{-1}$. C=C, C=O bond interactions were noted in peaks 1635 and $1394 \mathrm{~cm}^{-1}$. The observed result was in accordance with the other few reported results $[21,25]$.

Published By:

Blue Eyes Intelligence Engineering

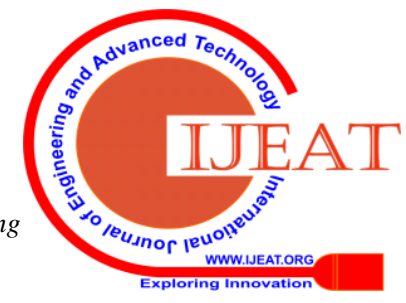




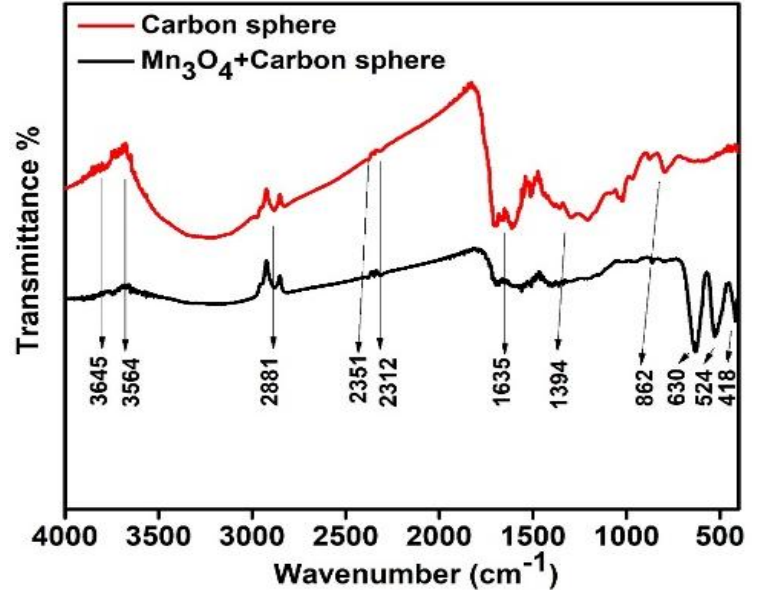

Fig. 3.FTIR spectra of (a) bare carbon spheres and (b) $\mathrm{Mn}_{3} \mathrm{O}_{4}$ decorated carbon spheres

\section{SEM and EDS analysis}

The (a) bare carbon sphere (b) $\mathrm{Mn}_{3} \mathrm{O}_{4}$ embedded on carbon spheres was shown in Fig. 4. The spherical formation of carbon spheres was witnessed from the SEM image fig. 3 (a). The $\mathrm{Mn}_{3} \mathrm{O}_{4}$ NPs embedding was clearly observed on the surface of the carbon spheres in the fig. 4 (b). The obtained result clearly state the formation of sphere shaped particles were formed and the $\mathrm{Mn}_{3} \mathrm{O}_{4}$ nanoparticles were wrapped as the outer surface of CSs uniformly. The agglomeration in $\mathrm{Mn}_{3} \mathrm{O}_{4}$ wrapped carbon sphere was due to van der waals forces attracted between carbon spheres and transition metal oxide. Fig.4. depicts the EDS spectrum and mapping of prepared $\mathrm{Mn}_{3} \mathrm{O}_{4}$ NPs coated on carbon spheres. From elemental mapping (figure.5) the elemental composition and uniform distribution of the prepared $\mathrm{Mn}_{3} \mathrm{O}_{4}$ NPs embedded on carbon sphere was determined. It clearly proves the purity of sample prepared. The morphology obtained was quite similar as observed in reported by Wu et al $[8,26]$.

\section{Electrochemical analysis}

The electrochemical behavior and redox properties of the as prepared $\mathrm{Mn}_{3} \mathrm{O}_{4}$ covered carbon spheres were investigated using Cyclic Voltammetry (CV) analysis. Fig.6. Reveals the $\mathrm{CV}$ curves of the $\mathrm{Mn}_{3} \mathrm{O}_{4}$ NPs coated on carbon spheres. The potential window was fixed between 0 to $+0.5 \mathrm{~V}$ and the current values changed in accordance with potential. Different scan rates from lower $5 \mathrm{mV} / \mathrm{s}$ to higher $100 \mathrm{mV} / \mathrm{s}$ were applied to find the redox behavior. The shift was observed in anodic and cathodic region, it denotes the internal resistance of the material with respect to the electrolyte/electrolyte interface.

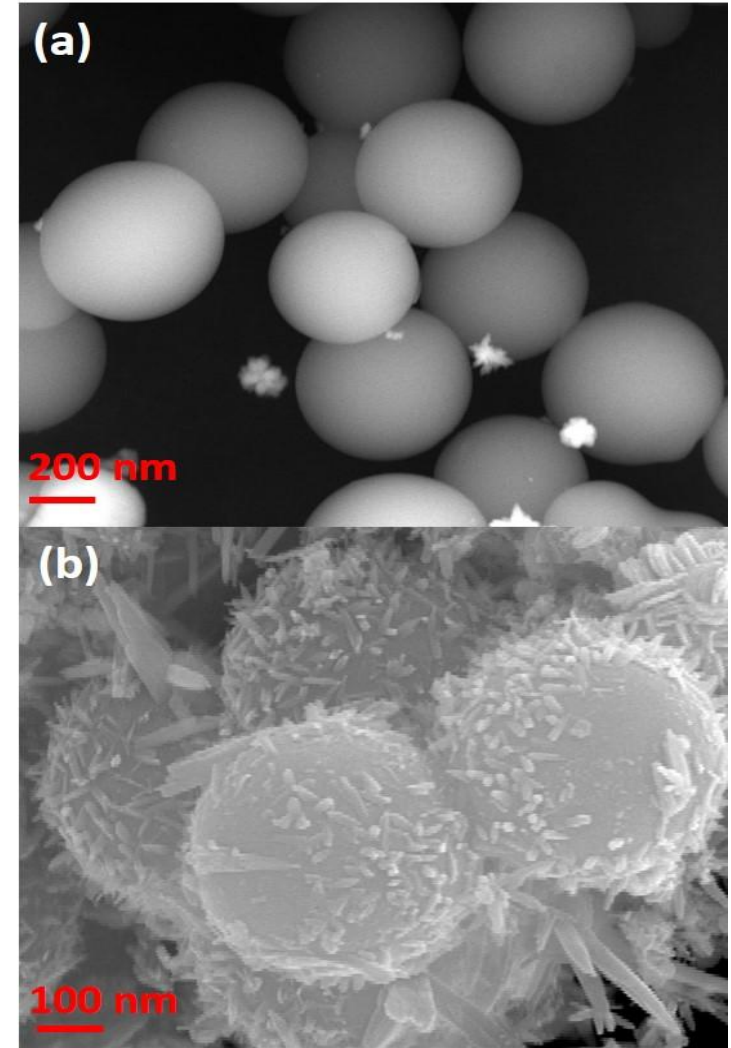

Fig. 4. SEM images of (a) bare carbon spheres and (b) $\mathrm{Mn}_{3} \mathrm{O}_{4}$ decorated carbon spheres
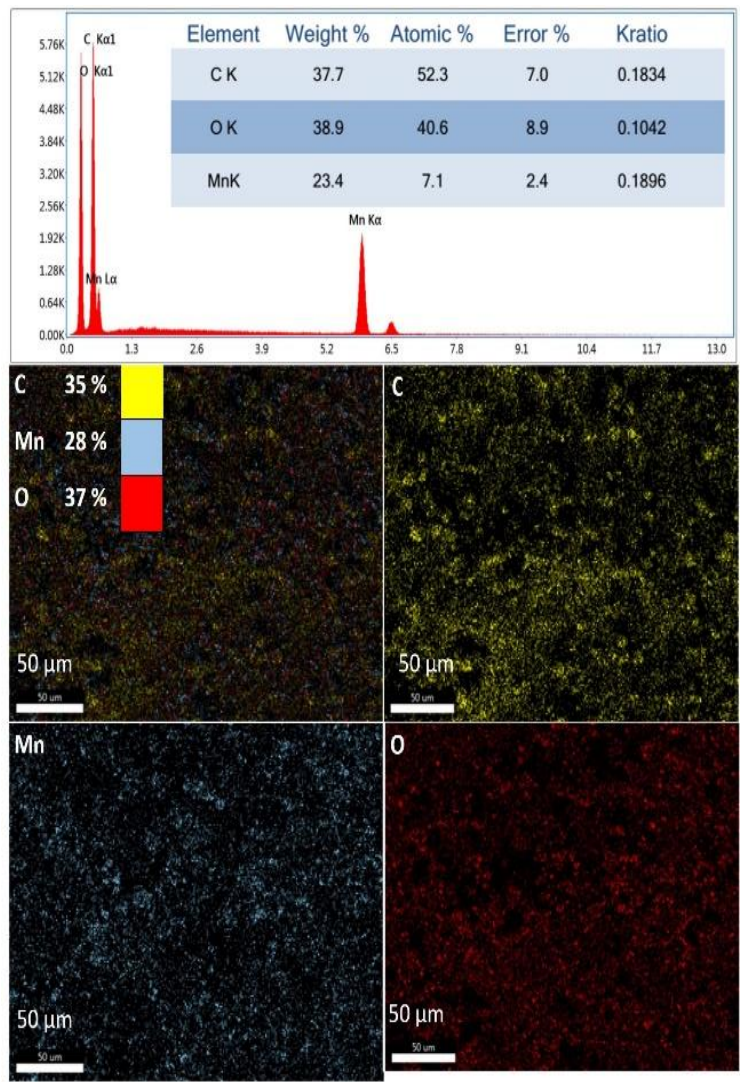

Fig. 5.EDS spectrum and elemental mapping of $\mathrm{Mn}_{3} \mathrm{O}_{4}$ NPs embedded on carbon spheres

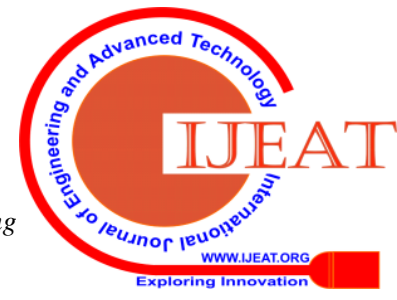




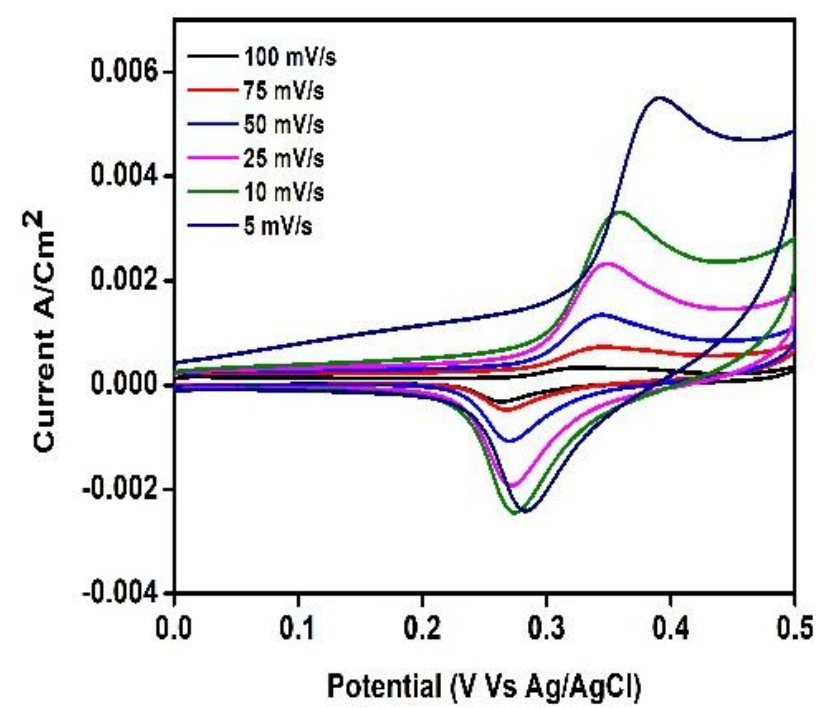

Fig. 6. CV curves of $\mathrm{Mn}_{3} \mathrm{O}_{4}$ decorated carbon spheres.

The charge-discharge mechanism of prepared $\mathrm{Mn}_{3} \mathrm{O}_{4}$ NPs decorated on carbon spheres was examined with the help of Galvanometric Charge-Discharge (GCD). Fig.6. shows the GCD curve of prepared $\mathrm{Mn}_{3} \mathrm{O}_{4} / \mathrm{CSs}$. The potential window was kept constant to the value from 0 to $+0.4 \mathrm{~V}$. The current applied varied from 0 to $0.5 \mathrm{~mA} / \mathrm{Cm}^{2}$. It is observed that, from the fig. 7 , for lower current the discharge capacity gained larger time due to the slower motion of ions inside the cell i.e., between electrode and electrolyte and lower discharge time for the higher current.

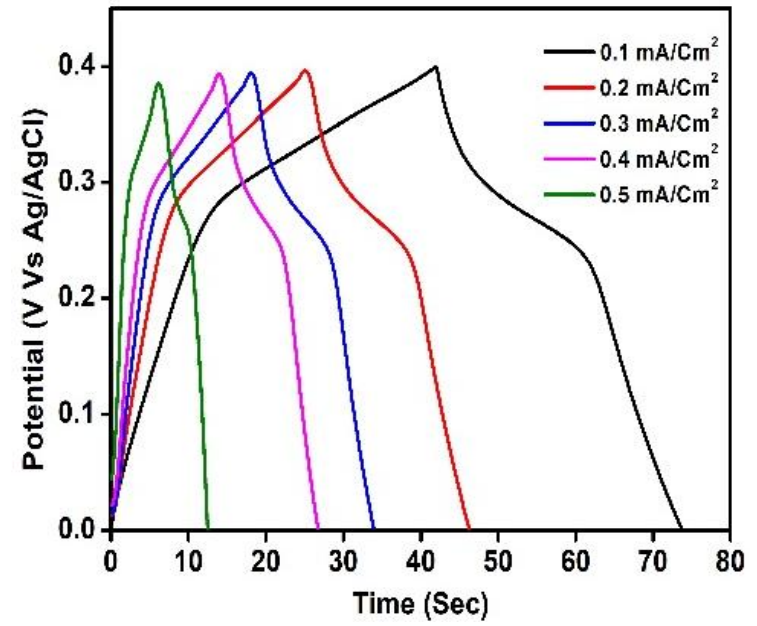

Fig. 7.GCD plateaus of $\mathrm{Mn}_{3} \mathrm{O}_{4} / \mathrm{CSs}$ nanocomposites.

The conducting property of the prepared $\mathrm{Mn}_{3} \mathrm{O}_{4} / \mathrm{CSs}$ nanocomposites was examined by electrochemical Impedance Spectroscopic analysis (EIS). Fig.8. reveals that the EIS curve of $\mathrm{Mn}_{3} \mathrm{O}_{4}$ NPs coated carbon spheres. The semi-circle with quasi spike clearly shows the resistive nature of $\mathrm{Mn}_{3} \mathrm{O}_{4}$ NPs coated on carbon spheres. The resistance value was found to be very low.

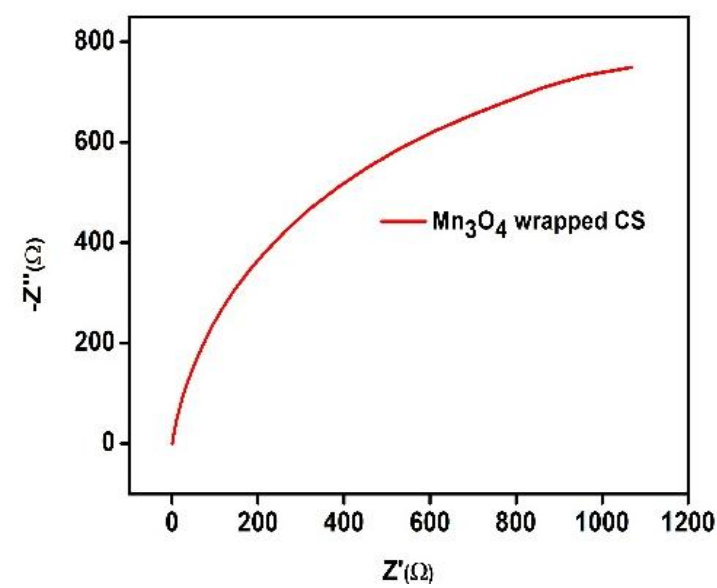

Fig. 8.EIS curve of $\mathrm{Mn}_{3} \mathrm{O}_{4}$ coated on carbon spheres.

\section{CONCLUSION}

In summary, the carbon spheres both pure CSs and $\mathrm{Mn}_{3} \mathrm{O}_{4}$ NPs embedded on carbon spheres were successfully prepared by facile hydrothermal method. The pure uniform carbon spheres size was measured $\sim 300 \mathrm{~nm}$. The crystal structure of prepared $\mathrm{Mn}_{3} \mathrm{O}_{4}$ material was found to be tetragonal structure that has wrapped on the surface of the carbon spheres were confirmed through SEM analysis. The diameter of both bare and $\mathrm{Mn}_{3} \mathrm{O}_{4}$ wrapped carbon sphere were found to have slight difference which further proved the coating of nanomaterials on the outer surface of carbon sphere. The functional groups with $\mathrm{C}-\mathrm{C}$ and metal oxide bond interactions were clearly observed through FTIR analytical technique. The combined composition of $\mathrm{Mn}_{3} \mathrm{O}_{4}$ and carbon prepared, and uniform distribution was confirmed with EDS analysis along with the mapping. The electrochemical activity such as reversible redox mechanism, charge-discharge property and conductance by movement of ions of as prepared $\mathrm{Mn}_{3} \mathrm{O}_{4}$ coated carbon sphere was examined and the obtained results were in coherence with one another.

\section{ACKNOWLEDGMENT}

The authors show their gratitude to IRC, Kalasalingam Academy of Research and Education (KARE) for providing research facilities and owe thankful for funding under University Research Fellowship (URF) scheme.

\section{REFERENCES}

[1]. S. Jun, S. H. Joo, R. Ryoo, and M. Kruk, "JACS_2000_122_10712.pdf," no. 11, pp. 10712-10713, 2000.

[2]. L. L. Zhang and X. S. Zhao, "Carbon-based materials as supercapacitor electrodes," Chem. Soc. Rev., vol. 38, no. 9, pp. 2520-2531, 2009.

[3]. "Evolution of Graphene Oxide and Graphene: From Imagination to Industrialization," ChemNanoMat, vol. 4, no. 7, pp. 598-620, 2018.

[4]. Z. H. Han, B. Yang, S. H. Kim, and M. R. Zachariah, "Application of hybrid sphere/carbon nanotube particles in nanofluids," Nanotechnology, vol. 18, no. 10, 2007.

[5]. R. Ranjithkumar, S. Ezhil Arasi, S. Sudhahar, N. Nallamuthu, P. Devendran, P. Lakshmanan, M. Krishna Kumar, Enhanced electrochemical studies of $\mathrm{ZnO}-\mathrm{CNT}$ nanocomposite for supercapacitor devices, Physica B Vol.568 (2019) pp.51-59.

[6]. Y. Hu, Y. Liu, H. Qian, Z. Li, and J. Chen, "Coating colloidal carbon spheres with CdS nanoparticles: Microwave-assisted synthesis and enhanced photocatalytic activity," Langmuir, vol. 26, no. 23, pp. 18570-18575, 2010.

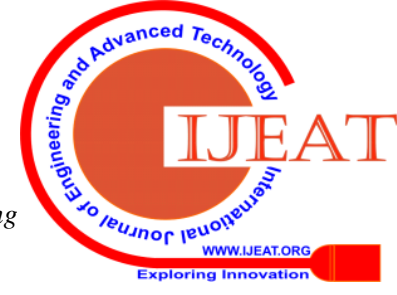


[7]. G. Krishnamurthy, R. Namitha, and S. Agarwal, "Synthesis of Carbon Nanotubes and Carbon Spheres and Study of their Hydrogen Storage Property by Electrochemical Method," Procedia Mater. Sci., vol. 5, pp. 1056-1065, 2014.

[8]. G. Wu, Y. Cheng, Y. Ren, Y. Wang, Z. Wang, and H. Wu, "Synthesis and characterization of $\gamma-\mathrm{Fe}_{2} \mathrm{O}_{3} @ \mathrm{C}$ nanorod-carbon sphere composite and its application as microwave absorbing material," J. Alloys Compd., vol. 652, pp. 346-350, 2015.

[9]. S.H. Lee, K.S. Lee, J.H. Yoo, Y. H. Jeong, H. S. Yoon, Trans. Electr. Electron. Mater, vol. 12, pp. 72, 2011.

[10]. A. A. Deshmukh, S. D. Mhlanga, and N. J. Coville, "Carbon spheres," Mater. Sci. Eng. R Reports, vol. 70, no. 1-2, pp. 1-28, 2010.

[11]. B. K. Mutuma et al., "Hollow carbon spheres and a hollow carbon sphere/polyvinylpyrrolidone composite as ammonia sensors," J. Mater. Chem. A, vol. 5, no. 6, pp. 2539-2549, 2017.

[12]. Z. Liang, H. Liu, J. Zeng, J. Zhou, H. Li, and H. Xia, "Facile Synthesis of Nitrogen-Doped Microporous Carbon Spheres for High Performance Symmetric Supercapacitors," Nanoscale Res. Lett., vol. 13, 2018.

[13]. S. Devi, T. Devasena, S. Saratha, P. Tharmaraj, and K. Pandian, "Dithiocarbamate post functionalized polypyrrole modified carbon sphere for the selective and sensitive detection of mercury by voltammetry method," Int. J. Electrochem. Sci., vol. 9, no. 2, pp. 670-683, 2014.

[14]. J. F. Weaver, "Surface Chemistry of Late Transition Metal Oxides," Chem. Rev., vol. 113, no. 6, pp. 4164-4215, 2013.

[15]. Y. Wang, J. Guo, T. Wang, J. Shao, D. Wang, and Y.-W. Yang, "Mesoporous Transition Metal Oxides for Supercapacitors," Nanomaterials, vol. 5, no. 4, pp. 1667-1689, 2015.

[16]. R. Sahoo, A. Pal, and T. Pal, Noble Metal-Transition Metal Oxides/Hydroxides. Elsevier Inc., 2019.

[17]. Y.-W. Yang, T. Wang, D. Wang, J. Guo, Y. Wang, and J. Shao, "Mesoporous Transition Metal Oxides for Supercapacitors," Nanomaterials, vol. 5, no. 4, pp. 1667-1689, 2015.

[18]. W. Wei, X. Cui, W. Chen, and D. G. Ivey, "Manganese oxide-based materials as electrochemical supercapacitor electrodes," Chem. Soc. Rev., vol. 40, no. 3, pp. 1697-1721, 2011.

[19]. A. KM, M. Manoj, B. Jinisha, P. VS, and S. Jayalekshmi, " $\mathrm{Mn}_{3} \mathrm{O}_{4} /$ reduced graphene oxide nanocomposite electrodes with tailored morphology for high power supercapacitor applications," Electrochim. Acta, vol. 236, pp. 424-433, 2017.

[20]. Y. Mi, W. Hu, Y. Dan, and Y. Liu, "Synthesis of carbon micro-spheres by a glucose hydrothermal method," Mater. Lett., vol. 62, no. 8-9, pp. 1194-1196, 2008.

[21]. P.Devendran, T.Alasan, K.Pandian, "Synthesis and Characterization of $\mathrm{Bi}_{2} \mathrm{~S}_{3}$ Nanorods Decorated on Carbon Sphere and Study its Electrochemical Application", Adv. Mat. Res. vol. 938, pp 215-220, 2014

[22]. R. Packiaraj, P. Devendran, S. Asath Bahadur, and N. Nallamuthu, "Structural and electrochemical studies of Scheelite type $\mathrm{BiVO}_{4}$ nanoparticles: synthesis by simple hydrothermal method," J. Mater. Sci. Mater. Electron., vol. 29, no. 15, pp. 13265-13276, 2018.

[23]. A. Shameem, P. Devendran, V. Siva, R. Packiaraj, N. Nallamuthu, and S. Asath Bahadur, "Electrochemical performance and optimization of $\alpha-\mathrm{NiMoO}_{4}$ by different facile synthetic approach for supercapacitor application,” J. Mater. Sci. Mater. Electron., vol. 0, no. 0, p. 0, 2019.

[24]. J. W. Lee and J. Kim, "S5P16-02 $\mathrm{Mn}_{3} \mathrm{O}_{4}$ Nanorods on Graphene Sheets for Advanced Supercapacitor Electrode," p. 19445, 2012.

[25]. X. Zhang et al., "Manganese dioxide core-shell nanowires in situ grown on carbon spheres for supercapacitor application," CrystEngComm, vol. 16, no. 19, pp. 4016-4022, 2014.

[26]. J. Yao, H. Wang, J. Liu, K. Y. Chan, L. Zhang, and N. Xu, "Preparation of colloidal microporous carbon spheres from furfuryl alcohol," Carbon N. Y., vol. 43, no. 8, pp. 1709-1715, 2005. 